\title{
Dissipation and Residues of Boscalid in Strawberries and Soils
}

\author{
Li Chen $\cdot$ Shuzhen Zhang
}

Received: 5 August 2009/ Accepted: 13 January 2010/Published online: 29 January 2010

(C) Springer Science+Business Media, LLC 2010

\begin{abstract}
Field experiments were carried out to investigate the dissipation of boscalid in strawberries and soils and its residual levels in strawberries at two different sites. Boscalid (50\% water dispersible granule) was applied at two dosages (349.5 and $525.0 \mathrm{~g}$ a.i./ha). Soils and strawberry samples were collected at $0,1,2,3,5,7,14,21$ days after application of boscalid. The results showed that boscalid dissipation pattern followed the first order kinetics with the half-lives of 4.9 and 6.4 days in strawberries and 6.1 and 8.0 days in the soils of Jinan and Beijing trail sites, respectively. The boscalid residues in strawberries were below the EU maximum residue level $(5 \mathrm{mg} / \mathrm{kg})$ after three days of application. This study suggests that boscalid is acceptable to apply for strawberries under the recommended dosage.
\end{abstract}

Keywords Dissipation · Residue · Boscalid · Strawberry · Soil

Boscalid is a carboximide fungicide developed by BASF as an alternative reagent to classic fungicides. It is a versatile,

L. Chen $\cdot$ S. Zhang $(\bowtie)$

Research Center for Eco-Environmental Sciences, Chinese Academy of Sciences, State Key Laboratory of Environmental Chemistry and Ecotoxicology, P.O Box 2871,

100085 Beijing, China

e-mail: szzhang@rcees.ac.cn

\section{Chen}

Institute of Plant Protection and Environmental Protection, Beijing Academy of Agricultural and Forestry Science, 100097 Beijing, China

e-mail: chenli517@126.com broad-spectrum, and highly environmentally compatible fungicide which is particularly ideal for use in high-end specialty crops such as fruits, vegetables, wine, and horticultural plants (Bardinelli et al. 2002; Matheron and Porchas 2004; Obanor et al. 2008; Raid et al. 2008; Smith et al. 2008). Boscalid has a unique mode of action to inhibit mitochondrial respiration, thereby inhibiting spore germination, germ-tube elongation, mycelial growth, and sporulation of pathogenic fungi on the leaf surface (Stierl et al. 2002). Further it has been evidenced to have relatively low toxicity to mammals and birds (USEPA 2003). The use of boscalid is believed to continuously increase because of these superior properties.

Strawberry (Fragaria glandiglora Ehrn) is a high-end fruit. Fruit rot diseases of strawberry (Fragaria $x$ ananassa Duch.) are serious problems for strawberry producers in many areas of the world (Xia et al. 2007). Recent studies have shown that boscalid is highly effective against fruit rot diseases and other diseases of strawberry and possibly be a new valuable reduced-risk pesticide in disease control (Wedge et al. 2007) due to the reason that some pathogens have developed resistance to the commonly used fungicides.

Very limited data have been reported concerning the dissipation and residue of boscalid in agricultural products since it is a relatively new fungicide. Jackson (2003) has investigated the field dissipation of boscalid in soil by using root zone model (PRZM-3) to validate a laboratory to field degradation conceptual model. Katagi (2006) has evaluated degradation of boscalid in pond and river. Another group (Chen et al. 2007) has reported the degradation of boscalid in cucumbers. However, no work has been conducted on the dissipation of boscalid in field soils and its residual levels in strawberries. Therefore, the aim of the present study was to investigate dissipation rate and 
residual level of boscalid in strawberry under field conditions.

\section{Materials and Methods}

Boscalid of analytical grade and its formulations (50\% water-dispersible granule, WG) were obtained from BASF China Ltd. All solvents used, i.e. dichloromethane, petroleum ether, acetone, acetic ester, and anhydrous sodium sulfate, were of analytical grade (Beijing Reagent Company, Beijing, China). Florisil SPE column (1,000 mg, $6 \mathrm{~mL}$ ) was purchased from DIKMA COM. Stock standard solution of boscalid was prepared in acetonitrile at the concentration of $500 \mathrm{mg} / \mathrm{kg}$.

The field trials including the dissipation experiments and ultimate residue experiments were carried out in two sites, Beijing (E116.46, N39.92) and Jinan, Shandong province (E117.01, N36.65), in April, 2008. The field experiment included three replicate plots and a control plot without application of the pesticide which was separated by irrigation channels, and the area of each plot was $30 \mathrm{~m}^{2}$.

After the maturation of the first strawberry, spraying with Boscalid 50\% WG formulation was carried out. The applied dose was $699.0 \mathrm{~g}$ a.i./ha. This level, twice as much as the recommend dosage level, was used in order to satisfy the detection limits in the experiment. Representative strawberry and soil samples $(0-10 \mathrm{~cm})$ were collected at intervals of $2 \mathrm{~h}$ and 1, 2, 3, 5, 7, 14, 21 days after spraying. The collected strawberry samples were comminuted with a blender (Philips, China) and stored in a freezer at $-20^{\circ} \mathrm{C}$ for further analysis.

The ultimate residue experiment was performed at the dosage level of $349.5 \mathrm{~g}$ a.i./ha (the recommended dosage) and $525.0 \mathrm{~g}$ a.i./ha (one and half times the recommended dosage), respectively. The first application was carried out after the first strawberry maturation. The following three applications were done at 7-days intervals. Representative strawberry and soil samples were then collected 3, 7 and 14 days after the last application of boscalid.

Twenty gram soil or strawberry sample was weighed into a $150 \mathrm{~mL}$-cone flask, and then $50 \mathrm{~mL}$ acetone was added. The cone flask was shaken on a shaker (HZQ-C, Haerbin Donglian Electron Technology Exploiter Co., Ltd., Heilongjiang Province, China) for $1 \mathrm{~h}$. The extracts of soil samples were filtered through the funnel using a fitter disk for cleanup with Flrosil SPE column. The extracts of strawberry samples were filtered under the vacuum through the funnel using a fitter disk. The aqueous residue was transferred into a $250 \mathrm{~mL}$ separate funnel containing $80 \mathrm{~mL} \mathrm{5 \%}$ saturated aqueous solution of sodium chloride, and then the sample solution was extracted by liquid-liquid partition with dichloromethane for three times at the volume of 40, 30 and $20 \mathrm{~mL}$, respectively. The dichloromethane layers were combined, passed through a funnel with anhydrous sodium sulphate and evaporated with the vacuum rotary evaporator (R-215; Switzerland Buchi Co., Ltd.) at $40^{\circ} \mathrm{C}$ to dryness (with weak nitrogen stream without disturbing the surface of the solution).

A Flrosil SPE column packed with $1 \mathrm{~g}$ Flrosil was washed by $10 \mathrm{~mL}$ of petroleum. The concentrated extract of different substrates were transferred to a column by $2 \mathrm{~mL}$ petroleum for three times and then washed by $15 \mathrm{~mL}$ petroleum/acetic ester (7:3, ratio volume), the eluate was collected and evaporated under vacuum at $40^{\circ} \mathrm{C}$ to dryness (with weak nitrogen stream without disturbing the surface of the solution). The residue was dissolved in $2 \mathrm{~mL}$ acetonitrile for quantitative analysis by HPLC.

All analyses were conducted with a Waters 2695 HPLC equipped with photodiode array detector (PAD). A reversephase $\mathrm{C}_{18}$ HPLC column $(250 \times 4.6 \mathrm{~mm}$ i.d., $5 \mu \mathrm{m}$ particle size) was used as the separation column and maintained at $30^{\circ} \mathrm{C}$. The mobile phase consisted of acetonitrile/water (60:40) with a flow rate of $1 \mathrm{~mL} / \mathrm{min}$. The injection volume was $10 \mu \mathrm{L}$, and the UV wavelength was $207 \mathrm{~nm}$. The retention time for boscalid was about $9.7 \mathrm{~min}$.

\section{Results and Discussion}

The fortified recovery, precision and limits of detection (LOD) of the analytical method were evaluated. Boscalid was added to untreated strawberry and soil samples at three concentration levels. Five replicates were set up for each treatment. The results are shown in Table 1 . The limits of detection (LOD) of boscalid in strawberry and soil samples were $10 \mu \mathrm{g} / \mathrm{kg}$ at a signal to noise ratio of 3 . The precision of the method in terms of relative standard deviations (RSD) ranged from 2.64 to $5.43 \%$. Chen et al. (2007) determined the residue of boscalid in cucumber with $\mathrm{GC}-$ ECD. Hiemstra and de Kok (2007) reported a multi-residue method for the target analysis of pesticides (including boscalid) in crops using liquid chromatography-tandem mass spectrometry. However, the method by GC needs derivalization and the mass spectrometer is not available in a normal laboratory. In this research, a simple and efficient HPLC method for the analysis of boscalid was developed, which can be an alternative for GC and LC-MS methods.

Figure 1 shows the dissipation pattern of boscalid in soil. The initial deposits of boscalid in the soil $2 \mathrm{~h}$ after application were 3.94 and $3.01 \mathrm{mg} / \mathrm{kg}$ for Beijing and Jinan sites, respectively. The dissipation of boscalid in soil was to the extent of 22.1 and $61.5 \%$ after 3 days of application for the two sites, respectively. Thereafter, its residue was found to decrease gradually and dissipation rates of 86.1 and $92.3 \%$ were observed 21 days after its application. The 
Table 1 Fortified recovery of boscalid in strawberry and soil sample

\begin{tabular}{lclll}
\hline Sample $(\mathrm{g})$ & Spiked amount $(\mu \mathrm{g})$ & Spiked concentration $(\mathrm{mg} / \mathrm{kg})$ & Average recovery $\pm \mathrm{SD}^{\mathrm{a}}(\%)$ & RSD $(\%)$ \\
\hline Strawberry (20) & 0.4 & 0.02 & $93.6 \pm 1.54$ & 3.44 \\
& 4.0 & 0.20 & $94.4 \pm 1.18$ & 2.64 \\
& 40.0 & 2.00 & $92.3 \pm 1.24$ & 2.76 \\
Soil (20) & 0.4 & 0.02 & $91.3 \pm 2.43$ & 5.43 \\
& 4.0 & 0.20 & $94.3 \pm 1.66$ & 3.72 \\
& 40.0 & 2.00 & $89.0 \pm 1.76$ & 3.94 \\
\hline
\end{tabular}

a The average recovery comes from five repetition

dissipation dynamics of boscalid can be described by the following first-order rate equation: $C=2.9616 \mathrm{e}^{-0.0866 \mathrm{t}}$ and $C=2.0388 \mathrm{e}^{-0.1139 t}$ with the square of coefficient $\left(R^{2}\right)$ of 0.924 and 0.905 for Beijing and Jinan sites, respectively. The half-lives of boscalid in the soils were 6.1 and 8.0 days for the two sites, respectively. This indicates that boscalid degrades a little more slowly in soil. Adsorption coefficient $K_{\text {oc }}$ for boscalid was from 670 to 1,760 (United States Environmental Protection Agency, office of prevention, pesticides and toxic substances (7501C), Pesticide fact sheet 128008), suggesting boscalid can be easily adsorbed on soil and remain at the surface soil after its application. The half-life of boscalid in soil was a little longer for Beijing site compared with Jinan site. The Beijing site has the following soil properties: soil organic matter, $1.50 \%$; sand, $61.0 \%$; clay, 27.9\%; pH 6.22. While the soil properties for the Jinan site are: organic matter, $1.40 \%$; sand, $39.8 \%$; clay, $43.7 \%$; $\mathrm{pH}$ 6.07. Difference in soil property might be the key influence factor for the degradation speed of boscalid.

The dissipation pattern of boscalid in strawberries is shown in Fig. 2. Boscalid dissipated rapidly after its application. The initial deposits of boscalid $2 \mathrm{~h}$ after application were 4.41 and $4.54 \mathrm{mg} / \mathrm{kg}$ in Beijing and Jinan

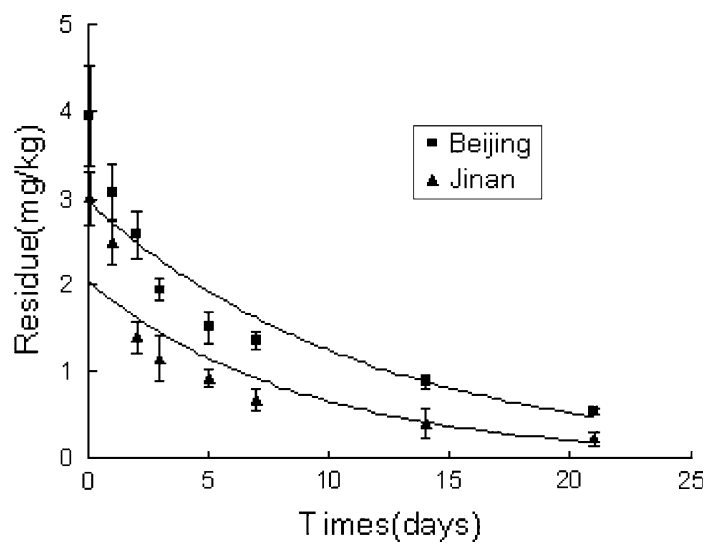

Fig. 1 Dissipation of boscalid in the soils sites, respectively. Its dissipation rates were 14.8 and $28.1 \% 1$ day after application, and then increased to about 83.1-93.2\% at the end of 2 weeks for the two sites. A sharp decline of boscalid concentration in strawberries was observed in the first 7 days after boscalid application. The dissipation dynamics of boscalid can be described by the following first-order rate equation: $C=3.4613 \mathrm{e}^{-0.1088 \mathrm{t}}$ and $C=3.5595 \mathrm{e}^{-0.1407 \mathrm{t}}$ with the square of coefficient $\left(R^{2}\right)$ of 0.938 and 0.932 for Beijing and Jinan sites, respectively. Boscalid degraded faster in strawberries than in soils, and its half-lives in strawberries were 4.9 and 6.4 days for the two sites, respectively. These results demonstrate that the rate of boscalid loss is high in strawberries.

Data of the ultimate residue are shown in Table 2. The concentration of boscalid in the strawberries and soils were detected after the application of boscalid at the levels of 349.5 and $525 \mathrm{~g}$ a.i./ha. As shown in Table 2, the residues of boscalid in strawberries and soils were lower 3 days after application than the EU maximum residue limit (MRL) of $5 \mathrm{mg} / \mathrm{kg}$. Therefore this study provides evidence that boscalid is acceptable to apply for strawberries under the recommended dosage. Based on the results of this study and the relevant residue regulations, boscalid residue levels will be acceptable when applied to strawberries in China.

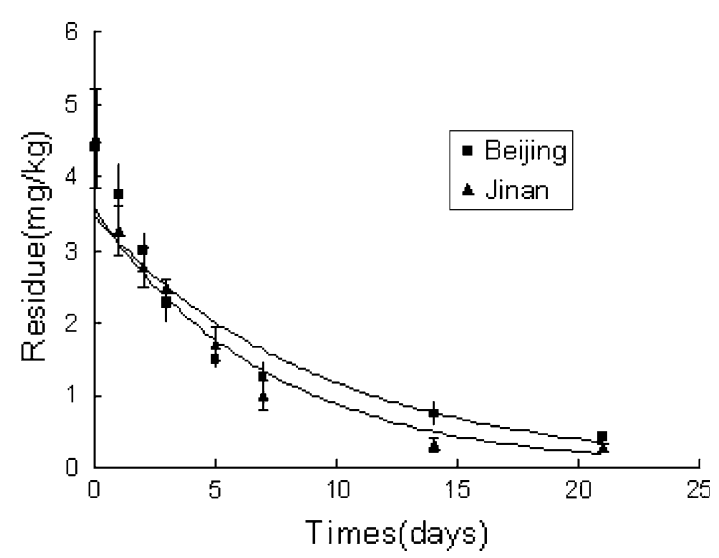

Fig. 2 Dissipation of boscalid in strawberries 
Table 2 Ultimate residue of boscalid in strawberries and soils (Beijing)

\begin{tabular}{|c|c|c|c|c|}
\hline \multirow[t]{2}{*}{ Dosage (g a.i./ha) } & \multirow{2}{*}{$\begin{array}{l}\text { Spray } \\
\text { times }\end{array}$} & \multirow{2}{*}{$\begin{array}{l}\text { Interval } \\
\text { (days) }\end{array}$} & \multicolumn{2}{|c|}{ Average Residue ${ }^{\mathrm{a}}$ (mg/kg) } \\
\hline & & & Strawberry & Soil \\
\hline \multirow[t]{6}{*}{349.5} & 3 & 3 & 0.296 & 0.235 \\
\hline & & 7 & 0.275 & 0.228 \\
\hline & & 14 & 0.168 & 0.172 \\
\hline & 4 & 3 & 0.516 & 0.308 \\
\hline & & 7 & 0.386 & 0.302 \\
\hline & & 14 & 0.195 & 0.212 \\
\hline \multirow[t]{6}{*}{525.0} & 3 & 3 & 0.691 & 0.980 \\
\hline & & 7 & 0.668 & 0.575 \\
\hline & & 14 & 0.430 & 0.232 \\
\hline & 4 & 3 & 0.925 & 1.686 \\
\hline & & 7 & 0.753 & 0.672 \\
\hline & & 14 & 0.575 & 0.562 \\
\hline
\end{tabular}

${ }^{a}$ The average recovery comes from three repetition

Obanor FO, Jaspers MV, Jones EE, Walter M (2008) Greenhouse and

Acknowledgments This study was supported by the project of study of residue of Boscalid in strawberry field sponsored by BASF China Ltd and the National Natural Science Foundation of China (Project 40730740).

\section{References}

Bardinelli TR, Ypema HL, Barnes JS, Wetzel HC, Chapman S (2002) Nicobifen (BAS 510 F): a new fungicide for use on vegetables, field crops and turfgrass. Phytopathology 92:S6 (Abst.)

Chen MF, Huang JW, Chien HP (2007) Residue analysis of fungicide boscalid in cucumbers following applications of boscalid $50 \%$ water dispersible granule. J Food Drug Anal 15:174-177

Hiemstra M, de Kok A (2007) Comprehensive multi-residue method for the target analysis of pesticides in crops using liquid chromatography-tandem mass spectrometry. J Chromatogr A 1154:3-25

Jackson SH (2003) Use of PRZM-3 to validate a laboratory to field degradation conceptual model. Pest Manag Sci 60:8-16

Katagi T (2006) Behavior of pesticides in water-sediment systems. Rev Environ Contam Toxicol 187:133-251

Matheron ME, Porchas M (2004) Activity of boscalid, fenhexamid, fluazinam, fludioxonil, and vinclozolin on growth of Sclerotinia minor and S. sclerotiorum and development of lettuce drop. Plant Dis 88:665-668 field evaluation of fungicides for control of olive leaf spot in New Zealand. Crop Prot 27:1335-1342

Raid RN, Pernezny K, Havranek N, Sanchez J, Saddler B (2008) Weather-based forecasting systems reduce fungicide use for early blight of celery. Crop Prot 27:396-402

Smith DL, Garrison MC, Hollowell JE, Isleib TG, Shew BB (2008) Evaluation of application timing and efficacy of the fungicides fluazinam and boscalid for control of Sclerotinia blight of peanut. Crop Prot 27:823-833

Stierl R, Hanke W, Lorenz G, Koehle H, Ammermann E (2002) Nicobifen (BAS 510 F) -biological characteristics and redistribution. Phytopathology 92:S79 (Abst.)

United States Environmental Protection Agency, office of prevention, pesticides and toxic substances (7501C), Pesticide fact sheet 128008 (2003) http://www.epa.gov/opprd001/factsheets/boscalid. pdf

Wedge DE, Smith BJ, Quebedeaux JP, Constantin RJ (2007) Fungicide management strategies for control of strawberry fruit rot diseases in Louisiana and Mississippi. Crop Prot 26:14491458

Xia YY, Meng ZHL, Li JQ, Zhang WH, Hou HL, Li YH, Zhou XY (2007) Studies on degradation and final residue of the bionic fungicide $o$-allylphenol in strawberry fruit by high performance liquid chromatography. Chin J Anal Chem 35:79-82 